\title{
Contemporary Building Planning as It Appears to a European Librarian
}

Mr. Vanderheyden is librarian, Fonds Bibliothèque Albert Premiere, Brussels, Belgium.

$\mathrm{I}^{\mathrm{T}}$ IS BY Now a platitude to hold that any I building should be "functional;" a library should be and should even resemble a library. Thus, the eyes and mind should be satisfied, and the library should be the efficient tool the patron as well as the librarian desires.

During the planning and building stage architects, engineers, members of the building committee, librarians and readers seem to agree on the surface at least. As soon, however, as the last soiled copies of the crumpled program leaflets of the dedication ceremonies have been picked up on the trampled lawns surrounding the new building, criticism develops. Everyone, except those who are directly responsible for the planning and construction of the building, finds fault with it. Few happen to know its inside story, the why's and wherefore's of some peculiar features, and in general the specific data of the complex problem which had to be solved.

It was not lightheartedly nor without a certain apprehensive hesitation that I tackled the problem of dealing with the American college and university building in this paper. Too many important "local" facts and data probably have escaped my attention or may have been obscured by considerations which are beside the point.

Much of the criticism that has been leveled at specific buildings fails to take into account the local conditions, habits and tra- ditions which often influence the nature of each building. Conversely, the attempt to copy plans of buildings that are successful in one place seldom works out satisfactorily.

No visitor on an American university campus can fail to observe that the library is in the very heart of things. It seems to play a more important part in the college and university life and activities than is the case in most European institutions of higher education and research. The social standing of the head of the institution, among the members of the college or university personnel, in general is higher than in most European universities. In too many cases the American's European colleague simply is looked upon as a donneur de livres and is treated as such. The only way he has to consolidate his position and standing in the university world is to obtain a part-time professorship in order to be at least on equal footing with most members of the teaching staff. If this teaching assignment is confined to a small course, it is all for the benefit of the person and the institution involved. Through this immediate and constant contact with the faculty members and a part of the student body, the librarian is bound to be more open to the changing needs of the teaching staff and students. This academic standing puts him in a position to defend the interests of the library at large, and eases the way for better relations with the smaller institutional and other special university libraries which are functioning under the direction of university professors. The American university librarian does not seem to need this halo. 
The building itself, which in many European university centers squeezes itself moderately between blocks of nonuniversity buildings, is a separate unit located in a conspicuous place on the campus. It often carries a symbolical decorative tower, or its massive volume or architectural treatment is so elaborate that it necessarily catches the visitor's eye. The library is considered an essential, not to say the central feature of any campus.. It has a symbolical value which in European universities is rarely stressed to the same extent.

The touching belief in the saving power of the printed word, the widespread belief in education in general, and the conviction that efficient research postulates adequate documentation-all these factors help to put any library on a marble pedestal. This conception of the important part it may play in the life of the individual, as well as of the community, brings forth generous financial contributions to cover the building and operating costs of these institutions.

The library facilities which are open to the faculty members and to the student body are far more numerous than in European institutions, and one cannot help feeling that the resources are more largely drawn upon. This is partly due to the fact that the lending policy is more liberal to students, as no professor's or instructor's countersignature is required on a call slip for books. Bibliographical assistance is given to students on a much larger scale than can be the case in European libraries, which are too understaffed to be able to carry on this type of work. This initiation into the use of the library and its bibliographical resources, is being organized more and more systematically. In some libraries the guide or leaflet giving factual information about the use of the library has grown into a more comprehensive and larger "library handbook" which the student may use through the years he spends in college or in the graduate school. Next to a fuller set of particulars on the library and its contents, on the service and facilities it offers, this handbook may contain advisory hints on bibliographies, thesis writing, the use of books in general, and reading, and may even give an outline of the history of the library and its collections. These guides-whether simple leaflets or larger handbooks - are extremely useful tools in the hands of the students. Owing to the uniformity in practices in American libraries at large, these manuals can be considered as suitable introductions to the use of any general library in the U.S. Noteworthy is the insistence with which some college and university librarians stress the need of teaching the use of the library to students.

This attitude of the university librarian stems, to a certain extent, from the simultaneous presence in the U.S. university of the undergraduate and graduate students, not to speak of the faculty. The demands and needs of these classes of readers are different, and the university library has to serve all of them. The dual character of its younger public has its bearing on its book stock, its service, and consequently on its organization and on the physical layout and arrangement of the building. Having to cater to a wide range of readers, from freshmen to research professors, the university library constantly has a varied set of new problems to face.

Service to the advanced students, research workers and professors is a routine job in any research library. The cooperation between librarians and this class of readers is easily established; as a rule these users of the library know the literature they want and are most willing to work in close cooperation with the staff.

The use of the available library material by the undergraduate, however, is a matter of constant discussion in the library 
world, as these readers have to be guided in the use of the library material-they have to be made conscious of the richness of library resources as well as of the benefit they may get out of the proper use of them.

In order partly to furnish both categories with their own tools and to find a solution for the overcrowding of a nonexpandable central library, in which both classes of readers had to be served, Harvard University went in for a bold solution. The undergraduate has his own library. This features a new trend in library use by undergraduates, as the overwhelming number of volumes are shelved in such a way that they are readily accessible to the students. Library users have to walk through a section of the stacks to reach the reading room. They are allowed to roam in the stacks all over the new building. This plan is another illustration of the general trend in American library policy to bring books and readers together as closely as possible.

The liberal lending policy so generously practiced by the library, the eagerness it shows to meet the students' high demands on the library resources, the systematic work to give the users of the library efficient guidance and bibliographical information, are intimately linked with a typical feature of American college and university education-the extensive personal work which is required from the student. If he spends fewer hours in the lecture halls than his European colleague, a much larger portion of his time is taken in by required reading and work on papers and reports he has to write in connection with his courses.

This feature of the American educational system logically places the library in a special position. It lays upon the library responsibilities which European institutions are not supposed to meet, at least not to the same extent. It calls for a special pattern of library organization, and as a result influences the general conception and layout of the plan.

Thus, the load of the public service no longer falls solely on the reference desk in the reading room, but on the general circulation desk which in libraries of any importance has been located outside the reading room. This formula of book delivery service is accepted by the American library public, as the idea of self-service permeates a number of every day life habits. A European visitor is not familiar with the widespread U.S. organization of the cafeteria system, nor with the super-market shopping system and its shopping buggies. Thus, a European reader generally expects that the volume he wants to read will not be handed across a general circulation desk, but will be brought to him at his desk in the reading room.

A remarkable feature of American library organization in general, and of college and university library policy in particular, is the re-establishment of direct contact between library material and readers. The unfortunate gap between the books and their users, which in the course of the nineteenth century result from the invention of the modern bookstack, has been better bridged in the U.S. than in most continental libraries. The open shelf policy, and still more so the open stack policy, as applied on such a large scale, can be considered as typical American correctives of the fundamental anomaly of the nineteenth century-library plan which broke up the previous rational simultaneous presence of books and readers, and even librarians, in one single space. The shelves in the reserve and special reading rooms are filled up with a tremendously large number of volumes, and the cubiculum system brings hundreds of readers to the stacks. There the reader is supposed to be seated near the material he seeks. It has to be admitted, of course, that this ideal often 
cannot be fully attained. Some popular subjects appeals to a larger number of students than others, and as a result it is not always feasible to seat every student near the ranges in which his material is shelved. Current, too, is the fact that the books and periodicals dealing with the subject a student is interested in are widely spread over several floors; thus the benefit of an intimate association with highly concentrated material, which is claimed as one of the assets of the system, is often illusory. It is, however, safe to presume that the carrel system, which partially restores a once broken unity in the essential library function of bringing readers and books together, will continue to characterize the U.S. university and college library organization and building as long as adequate financial means will be available to carry on the classification and the classified shelving of the new material.

The browsing room is another typical American institution, as almost every college and university library takes pride in the maintenance of an attractive recreational and cultural reading room. Designed to encourage cultural reading and develop good reading habits among students, it rightly is considered an essential part of the university library system. For if we agree upon the basic assumption that the university has to do more than supply the student with a training in the special scientific and professional field of his choice, and that the university as such is also responsible for the promotion of the student's general education, it is her duty to provide for the practical means to attain this goal. In most of our continental university libraries the book lending system is not the right means to promote the reading of this type of literature. In some cases it is not available, and the formalities for taking out books are too strict and complex. Our university authorities should be urged to take advan- tage of American experience and open a similar room in the university library.

It is interesting to note that in group discussions there is marked difference of opinion among librarians about browsing rooms. Some think they are unnecessary in an open shelf type of library.

These are, I think, some of the main points one has to bear in mind to understand the basic ideas of American college and university organization and planning in the past, as well as the new trends in shaping new forms for these old tools.

It is rather puzzling to a European visitor to find out that in the U.S. these reading rooms are in most cases "static" institutions as, generally speaking, books are not to be taken out. In some universities however, neither the library administration nor the university board has to worry about the popularity of their "browsing room," as this institution enjoys the favor of the student body by virtue of the excellency of the choice of the books on the shelves, and on account of the liberality with which students are permitted to draw on its resources. It has indeed grown out to a circulating library. Moreover, the room is a browsing room with a difference, as the student finds on its shelves not only the usual set of splendidly bound classics, but also the best works of modern authors together with the most popular books in all fields. The latest accessions are displayed on a special table, and a simplified special catalog tells all about the books that are readily available to the students. As a whole, the browsing room, and certainly the improved version of it, is a typical American achievement justifying pride.

In the early thirties the pattern of library buildings-both public and university-seemed to be in a state of flux.

Northwestern University Library, Rochester University Library, and to a certain extent the Yale Sterling Memorial Library 
seemed to be the outcome and climax of a movement in library planning of which the university libraries of Michigan, Minnesota and Illinois were earlier typical examples.

The architectural style of the building, if $\mathrm{I}$, as a librarian, am permitted to take up this matter, is in most cases historical (gothic or colonial) or, generally speaking, traditional.

More essential, however, are the characteristics of the plan: a large general reading room in front, separated from a solid special stack unit, which is located in the rear, by a delivery room and public catalog room; staff workrooms as far as feasible are on the main floor. Distinct architectural and structural library elements were provided for each of the three elementary but essential functions of the library: I. acquisition and preparation of the material; 2. storage of books; and 3. use of the library resources by the readers.

The Yale Sterling Memorial Library, however, was already pointing to a new trend. It was the first large university library in which the curbstone theory was put into practice, as the main public rooms were located on the first floor. Moreover a more intimate, closer relation between the stacks and the general reading rooms was created, although this feature was not so fully taken advantage of as in some continental libraries such as Zurich and Bern. In both cases the general circulation desk and the attendant's desk in the main reading room are linked together. Yale failed to do so, although it broke away from the common university library pattern and set an example followed by some smaller colleges which erected library buildings in the latter thirties. In some college and university libraries which later were built along the same lines, there has unmistakably been a tendency to do away with or to reduce the long distance which separated delivery desk and main reading room. The
University of Illinois offers an extreme example of the older school of thought; Yale, Agnes Scott, Temple, Loyola in Chicago, are illustrations of the newer conception.

As for the public libraries, something had been brewing for years since W. F. Poole had conceived his Newberry Library in Chicago along subject divisional lines. Milwaukee, Wisconsin, Cleveland, Ohio, Detroit, Michigan and Los Angeles had made attempts to find a satisfactory solution to the problem of bringing the reader in closer and easier contact with the material he was seeking. They partially succeeded, but the desire for monumentality from the side of the sponsors and architects of the building shattered the hopes of those who believed in the idea. This idea apparently is a sound one, and it never was abandoned. To split up the library resources in several fields, and bring them within the immediate reach of the readerdoing away as much as possible with what was once considered an unavoidable and essential link between the reader and the book, viz. the catalog cards and the call slips-seemed to some librarians to be the proper objective. Catalogs were described as obstacles which obscured the readers' sight. It was claimed that in this scheme better personal service could be given to the readers. Each special reading room would be staffed by a professional attendant who, by his special knowledge of the field in which he would be servicing his readers, would be in a much better position to interpret the literature on his special subject which is shelved in the reading room and in a contiguous space.

In the course of the thirties this theoretically sound idea made much headway and grew so popular that at present it is permeating the college library world more and more. The realizations of it in the public library sector were remarkable. In 
the thirties, Baltimore took the lead with its Enoch Pratt Free Library; Rochester, N.Y., followed and improved on the model; Toledo got its inspiration from the same source, and I was told that some Canadian libraries are being planned along the same lines. Brooklyn Public Library was a special case, and the story of its building sounds like a saga.

Along with the idea of the subject division reading room, which lies at the base of all these plans-if we leave Brooklyn out of the picture-is the curbstone theory, which is another essential part of the basic doctrine as embodied in these buildings. Readers should walk into the library and get their books just like a shopper walks into a department store and immediately faces the display counters.

Unlike the Boston Public Library, where many steps have to be climbed before the reader reaches the main entrance of this Florentine palace, or unlike the New York Public Library where 29 steps separate the Fifth Avenue sidewalk from the entrance level, most of these new buildings have their swinging or revolving doors almost at sidewalk level. Once inside the building no steps segregate incomers from the reading room, as in Boston or as in New York were 76 more steps have to be climbed, or even as in the more recent Columbia University Library, South Hall, where anybody looking for the general reference room, public catalog room, general delivery room, or main reading room may climb 46 steps.

As a result of this subject division room scheme the bulk of the books and periodicals which cannot be displayed in the reading rooms, and books which are seldom called for, are stored in a special section of the general storage space right underneath these reading rooms. This feature, common to all these open-plan libraries, means that numerous but simple vertical relations between the area in which the books are stored and the room in which they are used have been created.

A third feature of these buildings is their flexibility, at least as far as the reading space is concerned. For it is claimed that the larger area on the periphery of the first floor, which is taken in by the divisional reading rooms, can be rearranged to meet the changing needs and requirements of the readers. There are no partitions except bookcases seven feet high, and as these bookcases should not be fixed but movable, this plan should allow for any rearrangement and new allotment of space in case growing or decreasing use should call for them.

As a matter of fact this flexibility or fluidity is more theoretical than practical, as the bases of the bookcases, which form the partitions, are sealed into the floor, and as the vertical relation between reading rooms and storage space underneath is determined by fixed points in the plan, vix. the stairs. These stairs, placed within the area, allotted to the reading room staff, lead to the shelving space underneath. It is obvious that this feature is a rather weak spot in the scheme, but one wonders how it could be avoided.

It should be noted, however, that this claim upon flexibility is valid only for one of the three elements in the building; namely, the public rooms; and to a certain extent for the space allotted to the staff rooms. No attempt was made to have a building which would be flexible all over, in which stack space could be turned into reading space, or a service work room into a storage or public reading room. The building as a whole is only partially flexible.

Typical also for these buildings is the rectangular solid block form: the outer space on the periphery of the first floor is given to the different reading rooms, surrounding a central hall, in which the public 
catalog cases and the charging and return desks are placed. As a result only the corner reading rooms have windows on two sides, while four other rooms, which are getting daylight from the smaller side only, cannot rely upon natural light.

As for the relationships between the different elements (workrooms, storage space and public reading room area) staff rooms are located on the second or third floors. Even the printing shops and binderies are installed on the upper floors, although the experience of the Boston Annex (I918) might have shown the inconveniences of this arrangement. As the public catalog is on another floor, a copy of it has to be placed in the cataloging department.

The architectural style in all these buildings shows a timid tendency to depart from the historical style tradition-no Florentine palace as in Boston, although this public library may rank among the finest structures in the states; no copy of a Paris building in French Renaissance style as is the case in Cleveland; no imposing classical monumental building in white marble as the New York Public Library. This no longer was the ideal of the library builder in these thirties. Friendliness, and not aloofness; efficiency and not monumentality; informal simplicity and no overloading with decoration were the objectives aimed at in the quest for an adequate form to this new conception and new plan.

In the same period, I930-1943, the college, university and research libraries developed structurally and architecturally speaking along the traditional lines: a special storage space for the vast bulk of library resources, with carrels; a suite of administrative offices and rooms for the technical operations; and the usual set of public rooms, each group being treated in a different way.

It is noteworthy, however, that the trend of creating a closer connection between the main reading room and the stacks grew stronger, as the analysis of the plans of several college library buildings, which were created about that time, will show. In Temple University, Philadelphia ; in Loyola University, Chicago; and in Agnes Scott College Library, Decatur, Ga., the reading room is sealed to the stacks. It is likely that this shows the influence of the impressive example set by the remarkable Yale Sterling Library.

But developments on another plane would soon call for a far more important change in college library building. The traditional college educational policy in the use of books, as well as the college teaching methods, were subjected in some quarters to harsh criticism. The required reading system undoubtedly compels the student to do a certain amount of personal work. The basic idea of it is thoroughly sound; the way in which it works out, however, does not seem to be quite satisfactory. It has been observed that although the library may have tens or hundreds of thousands of volumes on its shelves, too many college students are said never to look for or use any other book than those assigned to them.

The value of the exclusive use by undergraduates of textbooks and of books put on the list of required collateral reading for most courses has been questioned, and a broader use of the library material advocated.

This called for a change in the concept of the library service, and consequently in library planning. A closer liaison between the teaching staff and the library staff for the acquisition and interpretation of the printed material was established, and the divisional or subject reading room, which had lately been adopted in several larger libraries, once more made its appearance in the college libraries. This meant the end of the general reading room. A larger stock of 
books and other live material on a special subject was put within direct reach of the students, and each reading room was administered by a member of the staff who was a specialist in that field. This would make for better service, as a student would dispose of a large collection of carefully selected books, and not of a small set of required reading material only. $\mathrm{He}$ would benefit from the permanent presence of a specialized interpreter of the material available in the room or in the stacks.

The new libraries of Brown University (1939), University of Colorado (completed 1939), and the Library of the University of Nebraska (completed early 1943) are three outstanding examples of this newer type. In them, the main stack is still in the middle of the rear, but the general reading room is replaced by a series of divisional reading rooms.

Columbia University's Butler Library (formerly South Hall) takes a place apart in the development. Having an enormous student population to serve, both in the college and in the graduate school, Columbia had a rather difficult problem to solve in attempting to supply general education and special research facilities to her student body and faculty members.

Hoping to promote the constant use of the largest number of books possible, a departmental reading room plan was adopted to make the library a laboratory.

Butler Library, indeed, has an impressive number of workrooms and carrels (426 in total), in addition to its college reading room, main reading room and a set of special reading rooms, all located on the periphery of the building. New in the history of university library building was the placing of the main stack in the center interior of the building starting in the basement and extending to the roof ( 15 tiers). This arrangement can be found in the later $\mathrm{Li}$ - brary of Congress Annex, and in the Bodleian Annex.

New in this stack construction was the attempt to bring about a certain amount of flexibility. Although the standard tier height was adopted $\left(7^{\prime} 6^{\prime \prime}\right)$, the shelving installed was built so as to be easily removable. This feature would allow for using any stack floor area for accommodation of individual readers or discussion groups as needed.

New also was the idea of taking all reference books out of the main reading room and putting them in a special reference department room, contiguous to the public catalog room, and located on the same floor as the main delivery room and main reading room.

To complete the picture, reference should be made to three more research libraries: the Virginia State Library, Richmond (1940), the Hoover Library (194I), and the Library of Congress Annex.

This new annex is a solid rectangular block, the core of which is formed by a multitier stack of about nine million volumes capacity, on top of which are located two reading rooms, surrounded. by two stories of small study rooms.

Flexibility is the keynote in the structure, and one of the remarkable features of the building. This flexibility, however, is not IoO per cent. It is in its stack structure that this building is remarkable for its bold innovations. One is the elimination of columns to the limits of practibility. The sectional area of the remaining columns has been increased; and thus it has been possible to do away with the network of thin structural columns which are a typical feature of the classical multitier stack construction.

A second innovation is the "hanging range." The bookstack is not a structural element, but it has not developed to a free 
standing shelving system either. The shelving is hung on the beams, thus allowing for a floor of one stretch, on which no base of a bookcase ever will leave a trace. This type of shelving, which is very easy to dismantle, enhances the flexibility of the stack space.

Noteworthy, too, is the use of shelving of a single standard length and width throughout the building. All shelving being interchangeable, it is constructed in such a way that volumes of all sizes can be shelved in all ranges on all tiers. This means that no special newspaper stack has been adopted, the newspaper volumes being shelved flat in a double range. Thus, the stack space is arranged for the most economical storage facilities for the largest number of volumes, with due allowance for the possibilities of shelving oversize books. The common size book is king.

After the beginning of World War II building stopped almost completely, but planning for the future was the order of the day, and at present planning new libraries is proceeding in more than 250 colleges and universities. Princeton was the first university to have its new library erected in the postwar era.

It should be noted that on the public library front things are quieter, although the old buildings in some large cities are totally inadequate, and some newer libraries no longer fulfil the requirements of modern standards.

In this sector remodeling and enlarging existing buildings, rather than planning brand new libraries, is under way or is contemplated.

In remodeling the buildings of Boston, Chicago or Buffalo, the prevailing trend seems to be the bringing of the main public rooms to the first floor. Next to it there is a general tendency to make the public rooms look friendlier and more attractive by the use of a sober decoration with light color schemes playing an important part in the interior treatment of the rooms. The days of the elaborate ceilings, dark colored walls and furniture seem to be over. The librarian has left his top hat at home together with his whiskers; he wears a carnation in the buttonhole of his light gray business suit.

More ambitious are the building plans that are ripening on the college and university campus.

The keynote of all this planning is to materialize the ideal of an expandable and flexible building.

The ever-growing abundance of library material is a pressing problem. Some newer libraries are already too small to house the mass of material accumulated.

In the period just behind us, the old library building was simply torn down or remodeled and adapted to other uses. At present, however, this course seems to be too costly, even in the U.S. The free space is becoming scarcer too, as some older campuses are getting rather crowded. The Harvard Yard is a typical case. Thus, American librarians are looking for solutions which resemble those which their colleagues in centuries-old institutions in the ruined or impoverished European countries had to adopt. I am referring to the opening of a deposit library (in Versailles for the Bibliothèque Nationale; in Colin Dale for the British Museum), and to the arranging of supplementary storage space in contiguous additions, which may even be underground stack space.

Those librarians, who cannot do without a new building and who have sufficient funds and an adequate free site, are aiming at erecting a building which is expandable -the first unit of which is only one portion of the building. In that case, however, it is required that the architect should propose 
a detailed and workable plan of the completed building as well as a workable plan that meets the immediate needs of the institution.

One cannot help feeling that this ambitious purpose is a utopian undertaking. Who is in a position to foresee what needs will have to be coped with in 20 or in 50 years so far as service to readers and storage problems are concerned? The storage of books may be worrying the librarian now, but the main issue is to bring about the best conditions for the use of library materials.

Stressing the problem of expansion is not a new feature in library architecture literature. What is new in this crusade is the underlying note of disillusionment, the lack of conviction with which this thesis is defended. Experience these last decades apparently has shown too clearly that unlimited expansion possibilities are utopian. The new Princeton building and the contemplated adoption of the rectangular solid block plan for the University of Pennsylvania Library constitute a denial of the practicability of this unlimited expansion theory. The course which was followed there proves that even these buildings are merely conceived, just like the older ones, as emergency quarters or provisional expedients.

There is, however, a striking difference between these plans and those which have been materialized in older libraries. Their departure from the older pattern lies, among other characteristics, in the aim for IOO per cent flexibility. The crusade for "fluidity" is on! The proposed libraries for the State University of Iowa and Washington State College seem to be the library buildings which are the best representative samples of the totally flexible type of library building, the idea being that any shift in use of any part of the building for any and every purpose should be possible in an easy and quick way. No space would be designed for any particular use solely. The planned library of the Massachusetts Institute of Technology will likewise have the same characteristic, as all floors will be built to provide accommodations for books, readers, library and teaching staffs, as the need may be.

This leads us to the discussion of what is new in the conception of the new college and university library.

As for the architectural style to be adopted, most European librarians have little to do with the problems of architectural style and design. They deem it wise to rely on their architect's good judgment and taste. They avoid this part of the work, hoping thus to make acceptable their firm stand on library matters proper. They are perfectly aware that eventual interference on their side would have no effect. The architect would simply let his wagon ride cheerfully in the worn ruts of traditional architecture or adopt a more modernistic design. $\mathrm{He}$ is the "master" of his work.

One cannot help feeling that some American librarians, who are associated with a building project, are conscious that they have a different problem to face. They seem to consider that as librarians they have certain responsibilities with regard to the architectural beauty of their library. A librarian, in their opinion, should not only be anxious to cooperate with the teaching staff in integrating the institution into the general educational scheme of the college, but he should also be aware of the importance of the educational value of the beauty of the campus buildings for the students.

This attitude may explain, to a certain extent at least, the importance of descriptions and considerations on matters pertaining to architecture and decorations in some writings by American librarians on library buildings. 
Americans are prone to complain of the limiting conditions which traditional architectural styles place upon the interior planning of a building, especially as they effect fenestration. They should remember that a competent architect can make any style do a good job if he will take the trouble to do so. By paying careful attention to window design, color, arrangement of furniture, and the shape of rooms, a friendly atmosphere can probably be created in any architectural style. One is amused by the slightly naive assumption that the lack of any architectural style will bring the best results.

Most significant are the implications of the theory of total flexibility or fluidity in the new college and university library buildings.

Another fact, too, is the impossibility of predicting the kind or nature of changes that may occur, or the importance of the probable growth to be expected. Therefore, an adaptable type of construction would be most welcome.

This idea in library buildings is not completely new. In almost any building program developed by librarians during the last 50 years, one finds the requirement formulated that the number of weight carrying walls should be limited to the utmost. Secondly, it has been a general rule to insist upon the necessity of avoiding any difference in level between stack floors and floors of public rooms and staffrooms. The result was that in most cases the suite of work rooms had twice the height of a stack tier. The height of the public rooms corresponded sometimes to three or four times this height. In this way a staff room could be converted into a public room. As matter of fact, this general provision aimed more at making possible an easy circulation of booktrucks, readers and staff members than at enhancing the flexibility of the building.

New, however, is the rigorism of this theory of adaptability. Flexibility is not to be limited to each of the three main groups of rooms in the building (stack, staff rooms and public rooms), but is to be applied to the building as a whole. An easy and quick rearrangement should be made possible.

There seems to be a difference of opinion among American librarians as to whether or not this theory will work only when applied to a certain kind of library organization: specifically, the open shelf, subject divisional arrangement. Its advocates deny the connection and maintain that all types of library organization can be accommodated. There are those who believe the idea is not suited to the more traditional order of things. What has probably happened is that those librarians who were interested in a more "progressive" type of program were also attracted by the newer and more "progressive" type of building. Thus, the two became linked. Their separability would seem to be proven by the fact that in its first unit, the State University of Iowa will use traditional organization of its space.

Likewise, there seems to have been some confusion between the idea of modular planning and various methods of construction. It should be clear now that a modular building can be made of "dry" steel construction with hollow columns serving as air ducts, or it can be built with reinforced cement floors and columns with separate air ducts. The merits and demerits of each system cannot be evaluated at this time.

This new concept of exchangeability, if it had been applied to such buildings as the Universities of Colorado and Nebraska, would have permitted them to expand or contract the size of their various divisional reading rooms to meet their current needs. This they cannot do at the present time.

It should be pointed out, however, that in a full building, space can merely be exchanged and not increased unless the size of the building is increased. 
Since the ceiling heights in these modular buildings is higher than in the typical stacks, there may be some wastage of space in the area devoted to book storage. This wasted space, however, could be used advantageously for dead storage. Also, it would be true that the loss would be more than made up by space saved in the reading room sections. The real basis of comparison will have to be made on the basis of the cost per square foot of floor space in the two types of buildings.

Since the modular buildings eliminate the multitier stacks, it is surprising, indeed, that the stack manufacturers have not tried to discourage librarians and architects against using them.

If all sections of the building are to accommodate stacks or people, the floor must be strong enough to support both. This might raise the cost somewhat. It will be interesting during the coming year to see whether the modular buildings prove to be as economical as early statements have claimed.

At first glance it would appear that the plans based on the subject divisional room idea, with their small reading rooms, would be expensive to administer, but careful scrutiny reveals that there is a difference between the staff costs of these buildings and those like Columbia. In reality these buildings do not have a large number of small rooms, but instead a few large rooms, broken into small sections by means of furniture. The divisional librarians serve not separate departments, but subject divisions. Thus, it is likely that these buildings will require a smaller staff than does the traditional building of the same size and service. This, however, is still an open question and one that should be watched closely.

The principal potential danger of the modular building is that its relatively low ceiling heights might not permit the installation of new systems of lighting and air cir- culation that might be developed in the future. They would have to get along with what they have.

Much of the lively discussion on what is the best method of organizing a university library seems to me to suffer from the fact that too many librarians fail to realize that a plan that is good for one campus may not be good for another. Thus, librarians have tried to apply the subject divisional plan to their universities without being certain that the right conditions existed.

One serious problem which a subject divisional library must solve is that of interdepartmental use of common materials. This is less serious than in a library based on a departmental organization, but it is more serious than in a library which puts everything in a separate stack. Here one must choose between conflicting values.

One also wonders what would happen if the books were shelved according to size rather than subject classification. Probably the reading room books would be arranged by subject and the stack collections by size.

It is good to notice that regardless of the type of organization, most of the new buildings are placing the most important reading rooms and public catalogs on the same floor as the technical processes rooms, and that this floor is usually at ground level. This is true of all of the very new buildings and of most of the ones built just before the war. An attempt at bringing together in a working arrangement on one level all the principal functions of the library has been made in a remarkable way in the Harvey S. Firestone Memorial Library at Princeton.

In closing, I am impressed by the vitality and quality of imagination shown in the planning of American college and university libraries, with the determination of the librarians to improve the quality of their service, and by the wealth at their disposal. Higher education is on the ascendancy in America. 